\title{
A doença sem nome: Traduzindo Caio Fernando Abreu
}

\author{
An illness without a name: Translating Caio Fernando Abreu
}

\section{Nícollas Cayann}

Tallinna Ülikool - TLÜ - Tallinn - Estônia

\section{Daniela Schwarcke do Canto}

Universidade Federal de Santa Maria - UFSM - Rio Grande do Sul - Brasil

\begin{abstract}
Resumo: A crise do HIV/AIDS revelou-se de altos níveis pandêmicos nos anos 1980/1990 acometendo principalmente a comunidade queer. Este período gerou ampla produção artística e literária não só na América do Norte, epicentro da pandemia, mas também na Europa e América Latina. Nesta mesma onda de produção literária se estabeleceu um campo tradutológico que se via responsável por traduzir os reflexos desta pandemia em diferentes regiões. Já um autor conhecido no Brasil, Caio Fernando Abreu, lança a coletânea de contos Os dragões não conhecem o paraíso, em 1988, um romance móbile de 13 contos. $O$ artigo aqui apresentado analisa o conto Linda uma história horrível, buscando estabelecer um diálogo entre a obra em português brasileiro e suas traduções para o inglês, por David Treece em 1990, e para o francês, por Claire Cayron e Alain Keruzoré, em 1991. No conto em questão, o autor estabelece um efeito estilístico, chamado aqui de metáfora predatória, que desempenha um papel importante em narrar a doença sem nome. $\mathrm{O}$ artigo trata de aspectos gerais das traduções, mas foca principalmente, utilizando-se dos processos de tradução comparada, em como a metáfora predatória foi ou não preservada em suas versões em inglês e francês, analisando também as implicações narrativas que foram causadas pela sua adoção ou ausência.
\end{abstract}

Palavras-chave: Caio Fernando Abreu, Os Dragões não conhecem o paraíso, Tradução Comparada.

Abstract: The HIV/AIDS crisis proved to be of high pandemic levels in the 1980s/1990s, affecting mainly the Queer community. This period generated extensive artistic and literary production not only in North America, the epicenter of the pandemic, but also in Europe and Latin America. In this same wave of literary production was established a tradutological field that was responsible for translating the reflexes of this pandemic in different regions. In 1988, Caio Fernando Abreu, a well-known author in Brazil, published a collection of 13 short stories entitled Os dragões não conhecem o paraíso (Dragons). The article presented here analyzes the tale Linda, uma história horrível (Beauty), aiming to establish a dialogue between the work in Brazilian Portuguese and its translations into English, by David Treece in 1990, and into French, by Claire Cayron and Alain Keruzoré, in 1991. In the story, the author creates a stylistic effect, named here as a predatory metaphor, which plays an important role in narrating the disease without a name. This article deals with general aspects of the translations, but focuses mainly on how the predatory metaphor was preserved or not in its English and French versions, as well as analyzing the narrative implications caused by its use or non-use.

Keywords: Caio Fernando Abreu, Dragons, Comparative Translation. 


\section{Introdução}

Os anos 1980 e 1990 foram marcados pelo surgimento e propagação de HIV/AIDS, a doença sem cura e até hoje assustadora. No princípio do surto pandêmico a enfermidade sem nome ficou conhecida como câncer gay, fato atribuído principalmente à matéria publicada pelo The New York Times em três de julho de 1981 cuja manchete dizia: "Rare Cancer seen in 41 homosexuals". Ficou conhecida ainda por um tempo como "GRID", sigla em inglês para Gay-Related Immune Deficiency (imunodeficiência relacionada aos gays), até que ganhasse seu nome definitivo: Acquired Immune Deficiency Syndrome (Síndrome da Deficiência Imunológica Adquirida), mais conhecido pela sigla AIDS. Este período deixou a comunidade queer severamente marcada tanto pelo vírus, pela doença, quanto pela perda de nomes importantes em diferentes ramificações da comunidade, e também pelo preconceito que crescia ao passo que a doença se disseminava.

O impacto da HIV/AIDS na historiografia da literatura de cunho queer é marcado por diferentes tipos de expressões artísticas. Embora os Estados Unidos tenham sido um epicentro da síndrome e que isso tenha fomentado uma larga produção literária sobre o tema, a América Latina também foi responsável por produções que reverberam a crise do HIV/AIDS. Caio Fernando Abreu foi um dos autores mais proponentes do Brasil, principalmente naquilo que se refere aos aspectos LGBTQ+, e publicou obras interessantes sobre a temática, como o romance móbile Os dragões não conhecem o paraíso (ABREU, 1988) onde está um dos seus contos mais interessantes e impactantes: Linda, uma história horrível.

Caio Fernando Loureiro de Abreu nasceu em Santiago do Boqueirão no ano de 1948. Dizem que com seis anos já escreveu seu primeiro conto, não deixando dúvidas de qual seria a sua paixão futura. $O$ menino mudou-se do interior para a capital Porto Alegre em 1963 para estudar, e já em 1967 publicou seu primeiro conto, O Príncipe Sapo na revista Cláudia. Em suas obras, Abreu fala de temas de interesse universal, como sexo, prazer, medo, solidão e morte de uma maneira clara e direta, sem formalidades e sem cerimônias.
Além de escritor, Abreu foi tradutor para o português do conto Assim Vivemos Agora (1986), de Susan Sontag, uma das obras ficcionais pioneiras na abordagem do tema da AIDS.

O livro Os dragões não conhecem o paraíso foi publicado em 1988 e é composto de 13 contos, mas a obra pode também ser lida como um romance fragmentado onde as 13 partes se somam, uma complementando a outra, e onde o amor está contado de todas as suas formas, em todas as suas nuances. $O$ próprio autor explica como essa leitura pode (ou não) ser realizada. Nas palavras de Caio Fernando Abreu:

\begin{abstract}
Se o leitor quiser, este pode ser um livro de contos. Um livro com 13 histórias independentes, girando sempre em torno de um mesmo tema: amor. Amor e sexo, amore e morte, amor e abandono, amor e alegria, amor e memória, amor e medo, amor e loucura. Mas se o leitor também quiser, este pode ser uma espécie de romance-móbile. Um romance desmontável, onde essas 13 peças talvez possam completar-se, esclarecer-se, ampliar-se ou remeter-se de muitas maneiras umas às outras, para formarem uma espécie de todo. Aparentemente fragmentado, mas de algum modo - suponho - completo (ABREU, 1988, p. 13).
\end{abstract}

Nestes contos, Abreu fala da dor do amor, da desilusão, da dificuldade de se encontrar em um corpo que já não é mais como antes, tendo envelhecido ou simplesmente amadurecido. Podemos notar em Linda, uma história horrível a descoberta da velhice da mãe que há muitos anos não via o filho, ou em Pequeno monstro, a descoberta do sexo no corpo que se desconhece como seu porque já não é mais de criança. Alguns destes contos são sobre doença, provavelmente sobre HIV/AIDS, ainda que o nome da doença nunca seja mencionado. Para tanto, Abreu utiliza um recurso narrativo que constrói a metáfora de doença que se baseia muito naquilo que se compreendia como os sintomas da doença ou como resultado de seus efeitos no corpo da pessoa acometida por tal enfermidade. Este exercício gera certo desafio tradutológico, visto que, ao passo que as metáforas de doença garantem a fluidez textual no texto em português, não necessariamente produzem 0 mesmo efeito nas traduções. 
Ao escrever Linda, uma história horrivel, conto integrante do livro Os Dragões não conhecem o paraíso (ABREU, 1988), o autor se assume como o primeiro escritor brasileiro a trazer o tema do HIV-AIDS para a literatura nacional. Em entrevista de 1995, Abreu declara: "pelo que sei, é a primeira ficção brasileira sobre AIDS" (CASTELLO, 1995, p. 5), mas Bessa, em Histórias Positivas: a literatura (des)construindo a AIDS (1997) confere esse título ao escritor Herbert Daniel: "A doença como tema, porém - ou, pelo menos, a tentativa de inscrevê-la como tal -, apareceu em 1987, no romance Alegres e irresponsáveis abacaxis americanos, de Herbert Daniel" (BESSA, 1997, p. 78).

Na obra de Abreu, a doença está presente nas entrelinhas, na apresentação do narrador e personagem sem nome que volta à casa da mãe depois de muitos anos, cumprindo o mito bíblico do filho pródigo. O personagem é descrito como um homem solteiro, de quase quarenta anos o que na época podia ser entendido como um estereótipo do homossexual masculino (embora isso seja severamente taxativo e preconceituoso), e, portanto, considerado principal grupo de risco ${ }^{1}$ nos anos 1980/1990. Esta caracterização aliada à informação das manchas na pele, da visível magreza e perda de cabelo, leva o leitor à percepção de que o protagonista seja portador da terrível doença. As manchas são o grande elo de ligação entre os personagens do conto. As manchas nas paredes da casa decaída, as manchas no pelo da cadela velha e nas mãos da mãe idosa, assim como as manchas no corpo do filho doente são o laço que os une à ideia de fim, de morte. É justamente a forma da escrita, repleta de metáforas e elipses, que torna a tradução do conto um exercício problemático, desafiando o tradutor nas suas escolhas linguísticas. As traduções em inglês (Beauty) e em francês (Belle, une histoire horrible) do conto Linda, uma história horrivel serão analisados aqui, através de recurso comparativo, naquilo que concerne às representações da metáfora de doença.

\footnotetext{
${ }^{1}$ Vale mencionar que as terminologias estereotipais não refletem a opinião dos autores do artigo, tão pouco a ideia de grupo de risco, que vem sendo debatida e realocada
}

\section{Traduzindo Caio}

No mundo ocidental a ideia de tradução é fundada no mito bíblico de Babel (COSTA, 2013). Ao longo da história do ocidente a tradução tem ocupado diferentes espaços em guerras, funções diplomáticas, funções literárias, comerciais, cumprindo exercícios práticos e dialéticos entre distintas comunidades. Contudo, parece que a função moderna da tradução ainda é confusa para muitos:

No entanto, a maioria das pessoas parece
não ter idéia do que é, realmente, o trabalho
do tradutor. Muita gente pensa que basta
saber falar uma língua estrangeira para que
se possa traduzir um livro escrito nessa
língua. Outros julgam que não Ihes seria
difícil traduzir para o português os livros que
lêem em inglês, francês, espanhol ou
italiano. Puro engano. A profissão de
tradutor exige, como todas as profissões,
longo período de aprendizagem. A técnica
da tradução é dificílima. Pode-se quase
afirmar que cada livro estrangeiro apresenta
certos problemas peculiares. Problemas que
exigem soluções diversas. (SILVEIRA,
1954, p. 9)

O conceito de tradução é apresentando, então, através de prismas variados em diferentes tradições literárias e tradutórias tanto no ocidente quanto naquilo que nomeamos de oriente. Isso demonstra que 0 tradutor não é apenas um leitor de língua estrangeira capaz de encontrar vocábulos similares entre diferentes línguas, mas sim um mediador de culturas. Podemos também dizer que o processo de comunicação humano ganha novo patamar com 0 ato de traduzir, pois a transição de ideias entre diferentes comunidades linguísticas se dá também pela tradução, logo o tradutor literário, por exemplo, é também responsável por uma mediação de culturas, por um trabalho de historiografia literária e responsabilidade textual que resulta em um ofício essencial às relações humanas.

Para Carvalhal (2003) a tradução é uma das possibilidades de modelos de leitura de um texto, expandindo os horizontes potenciais. Desta forma, nem o texto dito original, nem as traduções têm poder de exaurir o texto de sentido e fechá-lo para novas

conforme a realidade. Mas na época, anos 1980-90, acreditava-se que homossexuais eram mais suscetíveis ao vírus HIV, embora isso tenha se provado errôneo. 
interpretações, traduções e adaptações. Todas estes formatos apresentam traços de originalidade distintos, para Arrojo (1992), é impossível uma tradução não carregar consigo reflexos temporais referentes ao momento histórico em que é feita, a tradução tampouco é livre dos aspectos pessoais referentes ao tradutor e seus posicionamentos assim como seu nível de engajamento, logo, tanto o tradutor como a comunidade cultural na qual o texto/tradução se insere são sujeitos deste processo.

Pelas razões supracitadas e os desdobramentos que elas podem causar na conceitualização de um texto como original, decidimos então utilizar as seguintes legendas: LF para Língua Fonte, tratando-se da língua de primeira publicação de um texto, neste artigo referindo-se ao português brasileiro, na autoria de Caio Fernando Abreu; LM para Língua Meta, referindo-se ao idioma ao qual o texto em LF está sendo traduzido, neste artigo LM1 faz referência à tradução em inglês feita por David Treece (1990), enquanto LM2 faz referência à tradução em francês feita por Claire Cayron e Alain Keruzoré (1991).

Do ponto de vista da tradução, o livro Os Dragões não conhecem o paraíso (ABREU, 1988), apresenta vários aspectos interessantes que geram certa complexidade tradutológica. Um destes aspectos é a presença de dedicatórias: Abreu dedica os contos do livro para diferentes pessoas por diferentes razões, muitas das dedicatórias são para amigos, ou personalidades do cenário intelectual brasileiro, como por exemplo Fanny Abramovich e Márcia Denser. Estas dedicatórias são subtraídas da tradução em LM1 e são preservadas, em parte, na tradução para LM2. Pelas escolhas da tradução, supomos que somente as dedicatórias a ícones do mundo letrado brasileiro foram preservadas, e, talvez por essa razão, a dedicatória de Linda, uma história horrível não tenha sido mantida.

Outra questão notável em relação às diferenças entre as traduções é a substituição e a preservação de estrangeirismos. No livro em LF Abreu faz citações em inglês e em francês sem notas explicativas. Na ocasião da abertura do conto Uma praiazinha de areia bem clara, ali, na beira da sanga, Abreu introduz a narrativa por meio de uma citação de
Oscar Wilde: "Each man kills the things he loves". O autor opta por não traduzir os trechos de música ou poesias.

A tradução em LM2 preserva os estrangeirismos anglófonos utilizados por Abreu, como o uso de boy em a Dama da Noite que aparece em inglês na tradução em LM2 sem nota explicativa. Provavelmente pelo fato de que o uso de boy é bastante recorrente na comunidade queer, a nível internacional, como uma interjeição. Quanto às menções em francês a tradução em LM2 mantém em destaque e com nota explicativa de que já constava em francês no texto em LF. Contrariamente, a tradução em LM1 prefere buscar referenciais, sejam eles estrangeiros ou não, que sejam mais cabíveis ao gosto do tradutor assim como à comunidade leitora/mercado livreiro no qual a tradução será inserida em sua publicação. Como exemplo podemos notar o seguinte trecho em que a palavra francófona noir é inserida no texto em LF em francês grifada de itálico, enquanto o texto em LM2 preserva o vocábulo tal qual está em LF (apenas com nota explicativa, o texto em LM1 substitui a palavra por film noir, expressão mais recorrente em inglês):

\begin{tabular}{|c|l|}
\hline LF & $\begin{array}{l}\text { Se quiser eu piro, e imagino ele de capa } \\
\text { de gabardine, chapéu molhado, barba } \\
\text { de dois dias, cigarro no canto da boca, } \\
\text { bem noir (ABREU, 1988, p. 97). }\end{array}$ \\
\hline LM1 & $\begin{array}{l}\text { If I want I'll fantasise and imagine him in } \\
\text { a gabardine cape, with a wet hat, a two- } \\
\text { day-old beard, cigarette in the corner of } \\
\text { his mouth, real film noir stuff (ABREU, } \\
\text { 1990, p. 88). }\end{array}$ \\
\hline LM2 & $\begin{array}{l}\text { Si je veux je fantasme, et je l'imagine } \\
\text { avec une gabardine, un chapeau } \\
\text { mouillé, une barbe de deux jours, } \\
\text { cigarette au coin des lèvres, bien noir } \\
\text { (ABREU, 1991, p. 33). }\end{array}$ \\
\hline
\end{tabular}

Os contos têm a constante presença de excertos musicais. Tendo em vista o contexto brasileiro, mercado editorial no qual o livro foi publicado pela primeira vez, há um repertório significativo de referências à cultura brasileira, principalmente à cultura de cunho queer. Cazuza, compositor de Só as mães são felizes, canção que aparece na abertura do conto Linda, uma história horrível, já era um ícone do pop-rock brasileiro e foi de grande relevância no cenário LGBTQ+, principalmente nos seus últimos anos (1980 - 
1990). Acometido pela AIDS, o cantor que já era um estandarte da comunidade gay passou a ser também o garoto propaganda de campanhas de conscientização. Aqui podemos notar um ponto de convergência entre as traduções, pois tanto a versão em LM1 quanto em LM2 optam pela tradução não apenas do trecho como também do título da música, sem nota explicativa:

\begin{tabular}{|c|l|}
\hline LF & $\begin{array}{l}\text { 'Você nunca ouviu falar em maldição } \\
\text { nunca viu um milagre } \\
\text { nunca chorou sozinha num banheiro sujo } \\
\text { nem nunca quis ver a face de Deus." } \\
\text { (Cazuza: Só as Mães São Felizes) } \\
\text { (ABREU, 1988, p. 13) }\end{array}$ \\
\hline LM1 & $\begin{array}{l}\text { 'You've never heard of damnation } \\
\text { you've never seen a miracle } \\
\text { you've never wept alone in a dirty } \\
\text { bathroom } \\
\text { and you never wanted to see the face of } \\
\text { God.' } \\
\text { (Cazuza: Only Mothers Are Happy) } \\
\text { (ABREU, 1990, p. 2) }\end{array}$ \\
\hline LM2 & $\begin{array}{l}\text { Vous ne savez rien de la malédiction } \\
\text { et jamais n'avez vu de miracle } \\
\text { jamais n'avez pleuré seule dans des } \\
\text { toilettes sales } \\
\text { et jamais voulu voir la face de Dieu. } \\
\text { (Cazuza: Seules les Mères sont } \\
\text { heureuses) (ABREU, 1991, p. 7) }\end{array}$ \\
\hline
\end{tabular}

Em Linda, uma história horrível, apesar de Abreu não mencionar o nome da doença, ele faz um exercício de escrita literária que resulta em uma ascendente e consistente metáfora. A doença, que nunca é mencionada, atua quase como uma personagem da história, e vai aparecendo pouco a pouco na forma de manchas. No começo do conto as manchas estão no carpete, depois são borras no fundo da xícara, depois estão no teto, na mão de sua mãe, na cadela Linda, e assim elas vão desenvolvendo uma atmosfera hostil de sufocamento e perseguição que circunda o protagonista. Este artifício literário que dá movimento à doença sem nome, transformando-a em uma espécie de vilão que formula uma emboscada para o protagonista, é feito através de tropo. Aqui, optamos por nomear este processo como metáfora predatória.

O livro inteiro é sobre sexualidades disparatadas, que Abreu não nomeia mas metaforiza, conduzindo o leitor pela história. No caso do conto analisado, isso acontece com a uso de diferentes artifícios como: a) referência à ícones gays, como Cazuza; b) contextualização da doença sem nome como uma peste no noticiário televisivo; c) inferência indireta ao possível companheiro do protagonista; d) a presença do Sarcoma de Kaposi, tipo de câncer de pele que produz manchas de coloração roxa e que foi comumente associado à ideia de câncer gay durante a crise do HIV/AIDS. Destes recursos, o último é provavelmente o mais eficaz à nível internacional, e, portanto, o melhor trabalhado nas traduções.

Quando surgiram os primeiros casos da doença, as manchas eram vistas como marcas que mostravam ao mundo que a pessoa estava infectada. Eram como sinais, que não podiam ser escondidos, de que aquela pessoa era, de alguma forma, um "pecador", um transgressor das regras impostas pela sociedade homofóbica e preconceituosa, e por tal comportamento estava sofrendo castigo divino. $O$ autor se vale desse prejulgamento de que as manchas remetem a algo ruim, algo velho, arruinado, de alguma forma doente e decrépito, para transmitir ao leitor a percepção da doença. Abreu utiliza dois artifícios principais para transmitir a metáfora predatória das manchas: o uso da cor roxa e a repetição constante de derivações do substantivo mancha. Vejamos abaixo um quadro comparativo com trechos que exemplificam a tradução da metáfora predatória: 


\begin{tabular}{|c|c|c|}
\hline LF & LM1 & LM2 \\
\hline $\begin{array}{l}\text { E reviu o tapete gasto, antigamente } \\
\text { púrpura, depois apenas vermelho, } \\
\text { mais tarde rosa, cada vez mais claro, } \\
\text { - agora, que cor? (ABREU, 1988, p. } \\
\text { 13). }\end{array}$ & $\begin{array}{l}\text { And again he pictured to himself the } \\
\text { worn carpet that was once purple, but } \\
\text { then had faded to a sort of red and after } \\
\text { that turned pink - what colour was it } \\
\text { now? (ABREU, 1990, p. 2). }\end{array}$ & $\begin{array}{l}\text { Et il revit le tapis usé, autre-fois } \\
\text { pourpre, puis à peine rouge, et plus } \\
\text { tard d'un rose de plus en plus clair - à } \\
\text { présent, de quelle couleur? (ABREU, } \\
1991, \text { p. } 7 \text { ). }\end{array}$ \\
\hline $\begin{array}{l}\text { Por trás do jeito azedo, das flores } \\
\text { roxas do robe (ABREU, 1988, p. 14). }\end{array}$ & $\begin{array}{l}\text { The best way to get behind her sour } \\
\text { manner, get past the purple flowers on } \\
\text { her dressing-gown (ABREU, 1990, p. } \\
\text { 3). }\end{array}$ & $\begin{array}{l}\text { Par delà les manières revêches, les } \\
\text { fleurs violettes du peignoir (ABREU, } \\
\text { 1991, p. 9). }\end{array}$ \\
\hline $\begin{array}{l}\text { Fechou o robe sobre o peito, apertou } \\
\text { a gola com as mãos. Cheias de } \\
\text { manchas escuras (ABREU, 1988, p. } \\
\text { 15). }\end{array}$ & $\begin{array}{l}\text { She closed the dressing-gown over her } \\
\text { chest and held the collar with her } \\
\text { hands. Covered in dark patches } \\
\text { (ABREU, 1990, p. 4). }\end{array}$ & $\begin{array}{l}\text { tElle referma son perignoir sur sa } \\
\text { poitrin, serra le col avec ses mains. } \\
\text { Pleines de taches brunes (ABREU, } \\
\text { 1991, p. 9). }\end{array}$ \\
\hline $\begin{array}{l}\text { Manchadas de gordura, as paredes } \\
\text { da cozinha (ABREU, 1988, p. 15). }\end{array}$ & $\begin{array}{l}\text { The kitchen walls, stained with grease } \\
\text { (ABREU, 1990, p. 4). }\end{array}$ & $\begin{array}{l}\text { Les murs de la cuisine, tachés de } \\
\text { graisse (ABREU, 1991, p. 10). }\end{array}$ \\
\hline $\begin{array}{l}\text { A xícara amarela tinha uma nódoa } \\
\text { escura no fundo (ABREU, 1988, } \\
\text { p.15). }\end{array}$ & $\begin{array}{l}\text { The yellow cup had a dark stain in the } \\
\text { bottom (ABREU, 1990, p. 4). }\end{array}$ & $\begin{array}{l}\text { La tasse jaune avait une tache brune } \\
\text { au fond (ABREU, 1991, p. 10). }\end{array}$ \\
\hline $\begin{array}{l}\text { Ela tocou na mão dele, toque áspero } \\
\text { das mãos manchadas de ceratose } \\
\text { nas mãos muito brancas dele } \\
\text { (ABREU, 1988, p. 16). }\end{array}$ & $\begin{array}{l}\text { She touched his hand awkwardly, her } \\
\text { hands mottled with purple blotches } \\
\text { against his very white hands (ABREU, } \\
\text { 1990, p. 5). }\end{array}$ & $\begin{array}{l}\text { Elle lui toucha la main, un toucher } \\
\text { rêche de main tachées par la kératose } \\
\text { sur ses blanches mains à lui. } \\
(\text { ABREU, 1991, p. 12) }\end{array}$ \\
\hline $\begin{array}{l}\text { Ele fechou o isqueiro na palma da } \\
\text { mão. Quente da mão manchada dela } \\
\text { (ABREU, 1988, p. 16). }\end{array}$ & $\begin{array}{l}\text { He closed the lighter in his palm. Warm } \\
\text { from her stained hand (ABREU, 1990, } \\
\text { p. 5). }\end{array}$ & $\begin{array}{l}\text { Il serra le briquet au creux de sa main. } \\
\text { Tout chaud de sa main tavelée à elle } \\
\text { (ABREU, 1991, p. 12). }\end{array}$ \\
\hline $\begin{array}{l}\text { Aquele cinismo de telenovela não } \\
\text { combinava com o robe desbotado de } \\
\text { flores roxas, cabelos quase } \\
\text { inteiramente brancos, mãos de } \\
\text { manchas marrons segurando o } \\
\text { cigarro quase no fim (ABREU, 1988, } \\
\text { p. 17). }\end{array}$ & $\begin{array}{l}\text { That soap opera cynicism didn't go with } \\
\text { the faded dressing-gown, with the } \\
\text { purple flowers, her near white hair, her } \\
\text { nicotine-stained hands holding the } \\
\text { cigarette smoked down to the butt } \\
\text { (ABREU, 1990, p. 6). }\end{array}$ & $\begin{array}{l}\text { Un cynisme de feuilleton télévisé qui } \\
\text { n'allait pas avec le peignoir délavé aux } \\
\text { fleurs violettes, les cheveux presque } \\
\text { entièrement blancs, les mains } \\
\text { tavelées de bruns tenant une cigarette } \\
\text { presque éteinte (ABREU, 1991, p. } \\
\text { 13). }\end{array}$ \\
\hline $\begin{array}{l}\text { Olhava para cima, para fumaça do } \\
\text { cigarro perdida contra o teto } \\
\text { manchado de umidade, de mofo, de } \\
\text { tempo, de solidão (ABREU, 1988, p. } \\
\text { 19). }\end{array}$ & $\begin{array}{l}\text { She was looking up, at the cigarette } \\
\text { smoke losing itself against a ceiling } \\
\text { stained by dampness, mould, time and } \\
\text { solitude (ABREU, 1990, p. } 8 \text { ). }\end{array}$ & $\begin{array}{l}\text { Elle regardait en l'air, vers la fumée de } \\
\text { la cigarette qui se perdait au plafond } \\
\text { taché d'humidité, de moisi, de temps } \\
\text { et de solitude (ABREU, 1991, p.16). }\end{array}$ \\
\hline $\begin{array}{l}\text { Ela riu, vaidosa, mão manchada no } \\
\text { cabelo branco (ABREU, 1988, p. 20). }\end{array}$ & $\begin{array}{l}\text { She laughed, vainly, her stained hand } \\
\text { on her White hair (ABREU, 1990, p. 9). }\end{array}$ & $\begin{array}{l}\text { Elle rit, ostensiblement, en portant sa } \\
\text { mains tavelée à ses cheveux blancs } \\
\text { (ABREU, 1991, p. 17). }\end{array}$ \\
\hline $\begin{array}{l}\text { Jogou o casaco na guarda de uma } \\
\text { cadeira. E começou a desabotoar a } \\
\text { camisa manchada de suor e uísque } \\
\text { (ABREU, 1988, p. 22). }\end{array}$ & $\begin{array}{l}\text { He slung the jacket over the back of a } \\
\text { chair and began to unbutton his shirt, } \\
\text { stained with whisky and sweat } \\
\text { (ABREU, 1990, p. 11). }\end{array}$ & $\begin{array}{l}\text { Il jeta la veste sur le dos d'une chaise. } \\
\text { Et commença à déboutonner la } \\
\text { chemise tachée de sueur et de whisky } \\
\text { (ABREU, 1991, p. 20). }\end{array}$ \\
\hline $\begin{array}{l}\text { Acendeu a luz do abajur, para que a } \\
\text { sala ficasse mais clara quando, sem } \\
\text { camisa, começou a acariciar as } \\
\text { manchas púrpura, da cor antiga do } \\
\text { tapete na escada - agora, que cor? -, } \\
\text { espalhadas embaixo dos pêlos do } \\
\text { peito (ABREU, 1988, p. 22). }\end{array}$ & $\begin{array}{l}\text { He turned on the lamp, so that the room } \\
\text { would be lighter and, with his shirt off, } \\
\text { began to stroke the purple marks, the } \\
\text { same colour as the stair carpet had } \\
\text { once been - what colour was it now? - } \\
\text { that spread beneath the hairs on his } \\
\text { chest (ABREU, 1990, p. 11). }\end{array}$ & $\begin{array}{l}\text { II alluma la lampe à abat-jour, afin de } \\
\text { mieux éclairer la pièce lorsque, sans } \\
\text { chemise, il se mit à caresser les } \\
\text { taches violettes, de la couleur passée } \\
\text { du tapis de l'escalier - de quelle } \\
\text { couleur à présent? -, disséminées } \\
\text { sous les poils de sa poitrine (ABREU, } \\
\text { 1991, p. 20). }\end{array}$ \\
\hline $\begin{array}{l}\text { Deus, pensou, antes de estender a } \\
\text { outra mão para tocar no pêlo da } \\
\text { cadela quase cega, cheia de } \\
\text { manchas rosadas. lguais às do } \\
\text { tapete gasto da escada, iguais às da } \\
\text { pele do seu peito, embaixo dos pêlos } \\
\text { (ABREU, 1988, p. 22). }\end{array}$ & $\begin{array}{l}\text { God, he thought, and stretched out his } \\
\text { other hand to touch the near-blind dog, } \\
\text { its coat dappled with pink patches. The } \\
\text { same as those on the worn stair-carpet, } \\
\text { the same as those on the skin of his } \\
\text { chest, beneath the hair (ABREU, 1990, } \\
\text { p. 12). }\end{array}$ & $\begin{array}{l}\text { Mon Dieu, pensa-t-il, avant d'étendre } \\
\text { l'autre main pour toucher le corps pelé } \\
\text { de la chienne presque aveugle, } \\
\text { couvert de taches rosées. Semblables } \\
\text { à celles du tapis usé de l'escalier, } \\
\text { semblables à celles de son torse, sou } \\
\text { es poils (ABREU, 1991, p. 20). }\end{array}$ \\
\hline
\end{tabular}


Tendo em vista que a metáfora predatória é eficaz graças ao exercício da repetição e aproximação que conduz ao sufocamento/angústia do protagonista desde o começo do conto, onde ele percebe o tapete desgastado, até o final, quando ele revela as manchas roxas em sua própria pele, a princípio, é essencial que se preserve estes efeitos estéticos também na tradução. O autor faz uso constante das palavras mancha/manchado/manchada/manchas, utilizando apenas uma vez a variante nódoa, também sinônimo de mancha. Mancha é um vocábulo também comumente utilizado no meio médico em relação às consequências do HIV/AIDS, mencionado inclusive no Protocolo de Assistência Farmacêutica em DST/HIV/AIDS do Ministério da Saúde (2010). Deste modo, a palavra mancha e suas derivações são cabíveis tanto em termos médicos quanto em termos cotidianos como manchas de tapete, de umidade, e afins.

Em inglês os termos mais comuns para referirse à doença no âmbito médico são nodule e rash, palavras não utilizadas para outras condições, como manchas no tapete, por exemplo. A tradução em LM1 tenta promover o mesmo efeito metafórico do texto em LF utilizando os vocábulos Stain/Stained, apenas no final do conto o tradutor opta por utilizar a expressão "purple marks" (ABREU, 1990, p. 11), quando finalmente são reveladas as manchas roxas no peito do protagonista. Isso enfraquece, de certo modo, o uso da metáfora. Se levarmos em consideração que a função da repetição é mostrar que a mesma mancha que é vista circundando o protagonista finalmente executa sua função predatória e captura sua presa, a não repetição do vocábulo Stain/Stained no ápice do conto frustra o desfecho. Contudo, a utilização da palavra marks é adequada, principalmente no que diz respeito à inferência de castigo, de pessoa marcada, assim como os judeus do período nazista ou a heroína de Hawthorne, em A Letra Escarlate (1850), ou ainda na expressão shakespeariana marked to die (SHAKESPEARE, 1599), bastante recorrente no mundo anglófono.

Já a tradução em LM2 faz uma melhor preservação da metáfora predatória ao utilizar continuamente o substantivo tache e intercaladamente os particípios passados sinônimos taché/tavelé e suas variações de número e gênero. Ao optar pela repetição do vocábulo, os tradutores conseguem manter um impacto, derivado da constante presença das manchas, no desfecho do conto.

Quanto à questão da cor, ambas traduções são bastante consistentes: no texto em LF, Abreu faz o uso de púrpura e roxas, a tradução em LM2 preserva os vocábulos usando pourpre e violettes, e a tradução em LM1 usa purple em todos os casos. No começo do conto o protagonista fita um tapete antigo da casa de sua mãe, provavelmente sua casa de infância, e faz uma observação sobre as cores deste tapete: "antigamente púrpura, depois apenas vermelho, mais tarde rosa, cada vez mais claro, - agora, que cor?" (ABREU, 1988, p. 13); ao final do conto, perto do encerramento temos esta mesma colocação realocada, agora em relação às manchas no corpo do protagonista: "as manchas púrpura, da cor antiga do tapete na escada - agora, que cor?" (ABREU, 1988, p. 22), este jogo de espelhamento é preservado em ambas traduções.

Uma nuance final, que merece ser mencionada, é a distinção entre os diferentes males que afetam Linda e o protagonista. Embora nas últimas linhas do conto o narrador estabeleça que as manchas da cadela são iguais às do tapete $e$ iguais às do protagonista, declarando, então, uma espécie de similaridade no que diz respeito ao fim da vida, o autor parece definir, algumas linhas antes, um outro padrão de parâmetros: enquanto Abreu usa o púrpura para as manchas no peito do protagonista, ele usa a cor rosa para as manchas da cadela: "cheia de manchas rosadas" (ABREU, 1988, p. 22). O púrpura é a cor utilizada para o começo da vida do tapete que era "antigamente púrpura", logo o roxo e o púrpura não estão associados à velhice, já a cor atual do tapete gasto é rosa "cada vez mais claro" (ABREU, 1988, p. 13) é associada diretamente com os efeitos do tempo, assim como as manchas na cadela Linda, que são rosadas. Deste modo Abreu estabelece uma ideia de diferenciação entre os dois processos: as doenças e o mal que afligem Linda são consequências de sua velhice, tem relação com o final corriqueiro da vida, 
envelhecer e desfalecer, já o mal que acomete o protagonista é de outra ordem, não tem relação com o quão velho ele é, mas sim com outras condições, sendo assim eles se assemelham no sentido que ambos estão no fim, mas por razões distintas. A tradução em LM2 preserva as estruturas do texto em LF, causando o mesmo efeito fazendo o uso constante da palavra taches, já a tradução em LM1 faz uma diferenciação maior entre as manchas de Linda e as manchas do protagonista utilizando purple marks, para o protagonista, e pink patches para Linda. O protagonista de Linda, uma história horrível (ABREU, 1988) parece enfrentar 0 mesmo final que quase todos os personagens principais de sexualidade disparatada em Os Dragões não conhecem o paraíso (ABREU, 1988): o castigo.

\section{Conclusão}

A tradução é uma ligação entre duas línguas e duas culturas, línguas com estruturas e conceitos diferentes, e o seu objetivo primeiro deve ser o de dar ao leitor da língua de chegada acesso às informações transmitidas pelo texto em LF, o que nem sempre é tarefa fácil. Paulo Henriques Britto, já nas primeiras páginas de $A$ tradução literária, toca neste ponto:

"A questão é que as diferenças entre as línguas já começam na própria estrutura do idioma, tanto na gramática quanto no léxico; isto é, na maneira de combinar as palavras e no nível do repertório de 'coisas' reconhecidas como tais em cada língua. Pois um idioma faz parte de um todo maior, que é o que denominamos de cultura" (BRITTO, 2012, p. 14).

As escolhas do tradutor são, neste sentido, fator decisivo. A versão em LM2, de Claire Cayron e Alain Keruzoré, consegue manter um maior nível de preservação da estética literária de Caio Fernando Abreu, o que também certamente se deve ao fato de que tanto o português quanto o francês são idiomas latinos com uma variedade maior de vocábulos intercambiáveis. A tradução em LM1 nos parece mais ousada. Embora, no nosso ponto de vista, cometa um deslize no desfecho que compromete a eficácia da metáfora predatória, a tradução mantém com êxito o processo angustiante da metáfora no uso dos vocábulos. O tradutor opta, também, por algumas diferenciações mais severas que Caio Fernando Abreu no final do conto, ao comparar Linda e o protagonista. São duas traduções exemplares com abordagens distintas: a francófona (LM2) preza pela preservação não só da metáfora como do texto por completo, já a anglófona (LM1) é mais arriscada e, embora exista um compromisso com o texto em LF, podemos notar um cunho autoral mais latente.

\section{Referências}

ABREU, Caio Fernando. Os dragões não conhecem o paraíso. São Paulo: Editora Schwarcz, 1988.

ABREU, Caio Fernando. Dragons. Tradução de David Treece. Londres: Boulevard Books, 1990.

ABREU, Caio Fernando. Les dragons ne connaissent pas le paradis. Tradução de Claire Cayron e Alain Keruzoré. Paris: Editions Complexe, 1991

ALTMAN, Lawrance. Rare cancer seen in 41 homossexuals. The New York Times, Nova York, seção A, página 20, 3 de julho de 1981.

ARROJO, Rosemary. O signo desconstruído: implicações para a tradução, a leitura e o ensino. Campinas: Pontes, 1992.

BESSA, Marcelo Secron. Histórias positivas: a literatura (des)construindo a Aids. Rio de Janeiro: Record, 1997.

BRITTO, P. H. A tradução literária. Rio de Janeiro: Civilização Brasileira, 2012

CASTELLO, José. Não quero me encaixar em prateleiras: entrevista. O Estado de São Paulo, São Paulo, 09 de dezembro de 1995. Caderno 2, p. 5.

CARVALHAL, Tania Franco. O próprio e o alheio: ensaios sobre Literatura Comparada. São Leopoldo: Editora Unisinos, 2003.

COSTA, Patrícia Rodrigues. Do ensino de tradução literária. Dissertação de mestrado (Programa de Pós-Graduação em Estudos da Tradução). Brasília, Universidade de Brasília, 2013, 284 p. Disponível em:

https://repositorio.unb.br/bitstream/10482/15077/1/2013_Patricia RodriguesCosta.pdf . Acesso em: 23 de agosto de 2020.

HAWTHORNE, Nathaniel. A Letra Escarlate. Tradução de Sodré Viana. São Paulo: Martin Claret, 2006 [1850].

PROTOCOLO de assistência farmacêutica em DST/HIV/Aids. Ministério da Saúde, Brasília, 2010. Disponível em: <http://www.aids.gov.br/pt-br/pub/2010/protocolo-de-assistenciafarmaceutica-em-dsthivaids-2010> Acesso em: 23 de agosto de 2020

SHAKESPEARE, William. Hamlet. Oxford: Oxford University Press, 1987 [1599].

SILVEIRA, Brenno. A arte de traduzir. São Paulo: Melhoramentos, 1954

SONTAG, Susan, Assim Vivemos Agora. Tradução de Caio Fernando Abreu. São Paulo: Cia das Letras, 1995 [1986]. 


\section{COMO CITAR ESSE ARTIGO}

CAYANN, Nícollas; SCHWARCKE DO CANTO, Daniela. A doença sem nome: Traduzindo Caio Fernando Abreu. Signo, Santa Cruz do Sul, v. 46, n. 87, set. 2021. ISSN 1982-2014. Disponível em: <https://online.unisc.br/seer/index.php/signo/article/view/16666>.

doi:https://doi.org/10.17058/signo.v46i87.16666. 